
\title{
$\begin{array}{ll}\text { Research Square } & \begin{array}{l}\text { Preprints are preliminary reports that have not undergone peer review. } \\ \text { They should not be considered conclusive, used to inform clinical practice, } \\ \text { or referenced by the media as validated information. }\end{array}\end{array}$
}

\section{The Global, Regional, and National Burden and Trends of Infective Endocarditis From 1990 to 2019: Results From the Global Burden of Disease Study 2019}

\section{Huilong Chen}

Department and Institute of Infectious Diseases, Tongji Hospital, Tongji Medical College, Huazhong University of Science and Technology

Yuan Zhan

Department of Respiratory and Critical Care Medicine, National Clinical Research Center of Respiratory Disease, Tongji Hospital, Tongji Medical College, Huazhong University of Science and Technology

\section{Kaimin Zhang}

Department of medical engineering, Guangdong provincial people's hospital

Yiping Gao

Department of medical ultrasound, Tongji Hospital, Tongji Medical College, Huazhong University of Science and Technology, Wuhan, China Liyuan Chen

Department of Obstetrics and Gynecology, Wuhan No.1 Hospital

Juan Zhan

Department of Dermatology, Tongji Hospital, Tongji Medical College, Huazhong University of Science and Technology

Zirui Chen ( $0506712598 @ q q . c o m$ )

Second Clinical College, Tongji Hospital, Tongji Medical College, Huazhong University of Science and Technology

Zhilin Zeng ( $\nabla$ ulfnssul@sina.com )

Department and Institute of Infectious Diseases, Tongji Hospital, Tongji Medical College, Huazhong University of Science and Technology

\section{Research Article}

Keywords: Infective endocarditis, 2019 GBD, Incidence, Mortality, Disability-adjusted life years

Posted Date: September 17th, 2021

DOI: https://doi.org/10.21203/rs.3.rs-852855/v2

License: (9) (1) This work is licensed under a Creative Commons Attribution 4.0 International License. Read Full License

Version of Record: A version of this preprint was published at Frontiers in Medicine on March 9th, 2022. See the published version at https://doi.org/10.3389/fmed.2022.774224. 


\section{Abstract}

Objective: To compare and interpret the infective endocarditis (IE) burden and temporal trends globally and in different regions from 1990 to 2019.

Methods: Data on the incidences, deaths and disability-adjusted life years (DALYs) of IE were extracted and analysed from the Global Burden of Disease Study 2019.

Results: Globally, the number of IE cases and deaths has increased sharply during the past thirty years, and both presented an upward temporal trend annually. However, the estimated annual percentage changes (EAPC) of age-standardized DALYs demonstrated a negative temporal trend despite increasing DALYs. Moreover, graver IE burden was prone to males and aged patients. Meanwhile, different social-demographic index (SDI) regions had different disease burdens, and correlation analyses indicated that SDI presented a positive association with ASIR, no association with ASDR, and a negative association with age-standardized DALYs. Finally, we discovered positive associations of the EAPC of ASRs with the SDI in 2019 but few associations with the ASIR in 1990.

Conclusion: Generally, the global burden of IE is ever increasing, and the epidemiology presents substantial heterogeneity in different genders, ages and regions, which may help policy-makers and medical staff respond to IE and formulate cost-effective interventional measures.

\section{Introduction}

Infective endocarditis (IE) is a life-threatening cardiac infection caused by various microbes and is predisposed to occur in multiple cardiac valve conditions[1], with an annual incidence of approximately 3-10 per 100,000 people[2]. Globally, IE remains a highly pathogenic disease, with the overall mortality remaining unchanged at approximately $25 \%$, although antimicrobial therapy methods and surgical techniques have been improved in recent years[2; 3]. A population-based survey in France suggested that the age-standardized and sex-standardized annual incidence of IE was 33.8 cases per million inhabitants, the overall in-hospital mortality rate was $22.7 \%[4]$, and the high mortality of IE was likewise reported in developing countries[5]. The economic burden is heavy, as the inflation-adjusted expenditure on IE hospitalizations in the United States rose significantly from \$1.56 billion in 2003 to \$2.34 billion in 2016[6]. Therefore, increased efforts to reduce the burden of IE seem logical and needed[7].

The diagnosis and treatment of IE have developed rapidly but differ greatly in different regions and countries, resulting in the same substantial differences in disease burden worldwide. The contributing risk factors are diverse, including rheumatic heart disease, prosthetic valve or cardiac device use, intravenous drug use and other blood-borne microbial infections[8; 9]. Meanwhile, the complex and fickle clinical presentations and courses of IE brought about tremendous diagnostic and therapeutic challenges, and there were various response capacities among different regions[10]. Hidden cases in regions that have not kept up with updated diagnostic technology, such as valve uptake of ${ }^{\mathbb{V} F}$ F-FDG[8; 11] with elevated diagnostic sensitivity from 70\% to $97 \%[12]$, may remain undetected. Furthermore, a multispecialty heart valve team including an infectious disease specialist, cardiologist, and cardiac surgeon has been reported to reduce the time to surgery and both operative and long-term mortality[2; 13]. All these elements result in the heterogeneity of the IE burden between relatively high and low in-come regions.

The Global Burden of Diseases, Injuries, and Risk Factors Study (GBD) provides a systematic scientific assessment of disease and injury incidence, prevalence, and mortality, aiming at quantifying the relative magnitude of health loss due to risk factors, injuries and diseases by age, gender, SDI (sociodemographic index) and geographic location at a specific point in time[14; 15]. The systematic review of the $2010 \mathrm{GBD}$ study provided a plain epidemiological estimate of IE in most regions[16] and demonstrated the significant morbidity and mortality of IE. Here, by analysing the data from the 2019 GBD study, we aim to summarize comprehensive, transparent, and up-to-date estimates of incidence, death rate, DALYs and the corresponding agestandardized rate of the disease burden in 204 countries and territories, 21 geographic regions and 5 SDI regions, which may help policy-makers assess the burden of infective endocarditis, measure the progress of specific treatments, allocate resources, formulate relevant policies and assist health care providers in their clinical decision-making.

\section{Methods Data acquisition}

Global Burden of Disease 2019 (GBD 2019) provides the information about the burdens of 369 diseases and injuries along with 87 risk factors in the globe, different geographic areas, and 204 countries and territories[14; 17]. Data on infective endocarditis burden from 1990 to 2019 including its incidence, death, DALY, and their corresponding age-standardized rates (ASRs), were acquired from the Global Health Data Exchange GBD Results Tool (http://ghdx.healthdata.org/gbd-results-tool) (date of data extraction, 21 April of 2021). Here, as the case definition of 2019 GBD stated, included cases of IE were mainly based on clinical diagnosis[14]. Meanwhile, the information about the distributions of gender and age was also obtained. The rates were standardized according to the GBD world population and were reported per 100000 person-years. The GBD 2019 uses various interrelated parameters to measure population health loss, including number of cases and incidence, number of deaths and mortality, years of life lost (YLL) due to premature death, years lived with disability (YLD), and DALYs. As for the current report, we used the GBD Results Tool to extract estimates and their $95 \%$ certainty intervals (Cls) for prevalence of cases, deaths, and DALYs as measures of IE burden from 1990 to 2019 by region and country. To better exhibit the age distribution of IE burden, IE patients are classified into 5 groups, namely those aged under 5 years, from 5 to 14 years, from 15 to 49 years and from 50 to 69 years, as well as above 70 years. Social developmental index (SDI) is a composite indicator of total fertility, per capita income, and the years of schooling, which was formulated to reflect the social developmental degree. The value ranged from 0 to 1 , where 0 represents the fewest years of schooling, lowest per capita income, and highest fertility, whereas 1 represents the opposite. Previous studies have reported that the incidence and mortality of diseases might be affected 
by the social developmental degree. Base on that, the 204 countries and territories were classified into 5 groups according to the SDI quintile (low-SDI, lowmiddle-SDI, middle-SDI, high-middle-SDI, and high-SDI) to explore the association between infective endocarditis' burden and social development degrees in different regions.

\section{Statistical analysis}

The number of cases and deaths as well as age-standardized incidence, age-adjusted mortality, and age-standardized DALYs were the main metrics characterizing the IE burden and compared at the global, regional, and country levels. Cls were calculated from 1000 draw-level estimates for each parameter and $95 \% \mathrm{Cls}$ were defined by the 25 th and 975 th values of the ordered 1000 estimates; a $95 \% \mathrm{Cl}$ excluding 0 was considered statistically significant. To investigate the dynamic changes of IE burden, we further calculated the estimated annual percentage change (EAPC) to delineate the temporal trend in different ASRs of IE burden[18]. We performed a regression model fitting the natural logarithm of the ASR with the calendar year, namely, In (ASR) $=a+\beta *$ calendar year $+\varepsilon$, to estimate the EAPC with its $95 \%$ confidence interval $(\mathrm{Cl})$ based on the formula of $100 \times(\exp (\beta)-1)$. If the EAPC value and its $95 \% \mathrm{Cl}$ were both above zero, the change trend of ASR was considered upwards, and vice versa. Otherwise, the ASR was considered stable over time[19; 20]._In addition, we examined the shape of the association between ASRs of infective endocarditis and the SDI using the fit spline models[21]. Finally, we used Pearson's correlation test to analyze the correlation between EAPC and SDI in 2019 or ASIR in 1990 in 204 countries and territories. The maps were made using ECharts software. All statistical analyses were performed using GraphPad Prism 8 software.

\section{Results}

\section{Incidence of infective endocarditis}

As presented in Table 1, the incidence of infective endocarditis reached 1,090,530 in 2019 and 478,000 in 1990. The age-standardized incident rate (ASIR) increased from 9.91 per 100,000 population in 1990 to 13.80 in 2019, which showed an upward trend worldwide (EAPC, 1.2; 95\% Cl: 1.16-1.24). In the past thirty years, the incidence of IE in different SDI (sociodemographic index) regions rose in a relatively stable trend, and the incidence in males was higher than that in females (males: EAPC, 1.4; 95\% Cl: 1.36-1.45; females: EAPC, 0.96; 95\% Cl, 0.93-1.00) (Figure 1A, Table 1).

Globally, the incidences in different areas are divergent. In 1990, the high-middle SDI region had the most ASIR (11.34 per 100,000 population [95\% Cl: $9.44-$ 13.59]), the middle SDI region had the most incidence cases (159,200 [95\% Cl: 130,200-191,000]), while the incidence case or ASIR of the low SDI region was the lowest (30,590 [95\% Cl: 24,430-38,070]; 6.29 [95\% Cl: 5.23-7.50]) (Table 1). In 2019, the incidence of IE almost doubled, and ASIR increased by 1-4 per 100,000 population compared to 1990, although the distribution of incidence and ASIR remained unchanged. (Table 1). Among the 21 regions divided according to geographical characteristics, East Asia had the most ASIR in 1990 and was replaced by Tropical Latin America in 2019 (Figure 3 A, Table 1). The EAPC of ASIR in our datasets was positive in most regions apart from Western Sub-Saharan Africa and Southern Sub-Saharan Africa, which signifies that the IE incidence was on the rise. South America and Western Europe had high growth rates, while the growth rates in South Asia, Central Asia and Sub-Saharan Africa were relatively low (Figure 3D). The top three countries with the highest incidence of IE, Saint Lucia, Grenada, and Barbados, are all island nations (Figure $3 \mathrm{~A})$. In Figure 4A, ASIR and SDI are positively correlated $(R=0.58, P<0.0001)$, which seems to verify our results above. In other words, ASIR seems to be higher in relatively developed regions.

\section{Death of infective endocarditis}

Worldwide, there were 28,750 deaths in 1990 and 66,320 deaths in 2019 (Table 2). The age-standardized death rate (ASDR) (Figure 3B) and their changing trends varied among different countries (Figure 3E). Although the number of deaths in different SDI areas is increasing, their changing trend, namely, EAPC of ASDR, is not all rising. Moreover, females had more deaths from IE than males in 2019 (males: death, 32,630; 95\% Cl, 22,300-37,640; females: death, 33,690; 95\% Cl, 21,430-39,180) (Figure 1B, Table 2).

Although the low SDI region had the lowest number of deaths (2,960 [95\% Cl: 1,830-4,070]) in 1990, the mortality rate (ASDR, 0.9 per 100,000 population [95\% $\mathrm{Cl}: 0.55-1.38])$ was the highest, and it continued to be the region with the lowest number of deaths $(5,070$ [95\% $\mathrm{Cl}: 3,720-6,610])$ in 2019 . The high SDI region had the highest number of deaths (24,680 [95\% Cl: 11,730-30,810]) and ASDR (1.16 per 100,000 population [95\% Cl: 0.58-1.43]) in 2019 (Table 2). The EAPC of ASDR from 1990 to 2019 showed significant differences in ASDR between different SDI regions in the past 30 years. The ASDR of high SDI region grew fastest (EAPC, 2.01 [95\% Cl: 1.51-2.51]) while the ASDR of middle (EAPC, -0.62 [95\%Cl: $-0.76--0.48]$ ) and low SDI regions (EAPC, -0.56 [95\%Cl: $-0.64--0.48]$ ) is decreasing (Table 2), which is different from the continuous increase of death number in each SDI region in the past 30 years as shown in Figure $1 \mathrm{~B}$. Between the 21 regions, Oceania had the lowest number of deaths in both 1990 and 2019, while the region with the highest deaths changed from East Asia in 1990 to Western Europe in 2019 (Table 2). Furthermore, southern Latin America and Oceania had the highest and second highest ASDRs in 1990 and 2019, respectively (Figure 3B, Table 2). Fascinatingly, East Asia, which had the most deaths in 1990, held the lowest ASDR in 2019 and declined fastest in ASDR from 1990 to 2019 (EAPC, -2.4 [95\% Cl: -2.78- -2.02]). The EAPC of ASDR of different regions is quite heterogeneous. High-income North America, Western Europe and Eastern Europe had relatively high growth rates, while East Asia and Western Sub-Saharan Africa had relatively high decline rates (Figure $3 E$, Table 2). The ASDR was not correlated with the SDI $(R=-0.06, P=0.10)$, which means there was no specific relationship between the ASDR and SDI even if the high SDI region had the most deaths and ASDR in 2019 (Figure 4B, Table 2).

\section{DALYs of infective endocarditis}


The DALY attributable to IE was on the rise globally from 1,118,120 in 1990 to 1,723,590 in 2019, with a preference for males (Table 3, Figure 1C). However, the age-standardized DALYs changed from 22.78 per 100,000 population in 1990 to 21.93 in 2019 around the world, and the EAPC of age-standardized DALYS was negative in both sexes. The middle SDI region obtained the highest DALY in both 1990 and 2019, as the low SDI region had the lowest DALY. Moreover, the low SDI region retained the highest age-standardized DALYs in 1990 and 2019. Regionally, the DALY was found to be highest in East Asia in 1990 (225,160 [95\% Cl: 123,240-291,150]) and South Asia in 2019 (287,100 [95\% Cl: 225,890-360,890]). The age-standardized DALYs of Southern Latin America, Oceania and Southeast Asia were relatively high in both 1990 and 2019, whereas those of East Asia, Central Asia and Central Europe were relatively low (Table 3, Figure 3C). Interestingly, Eastern Europe (2.81 [95\% Cl: 2.35-3.27]) and High-income North America (2.66 [95\% Cl: 2.01-3.32]) held the highest EAPC of agestandardized DALYs (Table 3, Figure 3F).

As shown in Figure 3B and Figure 3C, the distribution of countries with age-standardized DALYs and ASDR in 2019 was similar. Kiribati, Fiji and American Samoa are the top 3 countries both in the ranking of ASDR and the age-standardized DALYs in 2019. Moreover, the countries that held the lowest ASDR, such as China and Azerbaijan, had the lowest age-standardized DALYs simultaneously. Thailand and Grenada, the country with the first and second place of EAPC of ASIR, is also the second and third place in EAPC of age-standardized DALYs. The country with the largest change in DALY was Kiribati (Figure $3 F)$. In Figure 4C, the SDI negatively correlated with age-standardized DALYs $(R=-0.40, P<0.0001)$, which means that the more developed region is more likely to have lower DALYs.

\section{Age distribution}

Age distribution is likewise a vital parameter of IE epidemiology. Globally, patients aged 50 years or older presented nearly $63 \% \mathrm{IE}$ incidence (Figure $2 \mathrm{~A}$ ) and $79 \%$ IE mortality (Figure 2B) in 2019, significantly outnumbering the incidence and mortality in 1990 ( $35 \%$ and $60 \%$, respectively). This signified the great disease burden in aged patients, especially in relatively developed regions. In contrast, patients aged under 14 years had an evident decline in IE incidence and mortality in 2019 compared with 1990 (incidence: 31\% to 12\%; mortality: 15\% to 3\%), which demonstrated the obviously improved IE effect on young individuals as society progressed. However, the morbidity and mortality of the youngers remained relatively high in low SDI regions. For DALYs, although there was an upward trend globally (Figure 2C), the age-standardized DALYs and EAPC were both decreased (Table 3). Interestingly, the IE patients aged under 5 years had a major number of DALYs in 1990 but almost decreased to the lowest in 2019, and the same changes in this age group were observed in all SDI regions. Generally, despite varying greatly in different age groups in different regions, the IE burden predominately affected the elderly and showed an alleviation in the youngers.

\section{The correlation between EAPC and SDI in 2019 or ASIR in 1990}

A significant positive association was found between the SDI and EAPC in 2019, regardless of the EAPC of the ASIR ( $r=0.47, p<0.001)$, ASDR $(r=0.35, p<$ $0.001)$, or age-standardized DALY rate $(r=0.32, p<0.001)$ (Figures $5 A$, Figure 5B and Figure $5 C)$. These scatter plots indicate that the more developed the region is, the more likely it is to change the disease burden. Furthermore, we analysed the association between ASIR in 1990 and EAPC of ASRs, all presenting no distinctiveness (Figure 5D, Figure 5E, Figure 5F), which demonstrated that the baseline IE incidence in 1990 had no significant impact on annual changes in IE burden.

\section{Discussion}

In this study, we assessed the latest infective endocarditis burden and temporal trends of incidence, mortality and DALYs in 204 countries and territories, 21 geographic areas and 5 SDI regions and analysed the relationship between the statistics. Generally, the incidence of IE has been on the rise in most regions worldwide during the past thirty years. However, the trends of mortality and DALYs were heterogeneous across regions and countries and varied among different SDI regions. Meanwhile, the impact of gender and age on the ASIR and ASDR of IE are also prominent, with a preference for morbidity in males and elderly individuals. Furthermore, we determined that the SDI in 2019 was associated with the EAPC of these three parameters above. Therefore, the systematic understanding of global epidemiology for IE and the specific change pattern in disease burden may be valuable for public health officials and policy-makers to develop the corresponding prevention and control measures and allocate rational medical resources.

As our article showed, the cases of IE increased year by year between 1990 and 2019, as did the incidence in the vast majority of countries, corresponding to previous studies[22; 23]. The noteworthy changes in the incidence and epidemiology of IE worldwide might be ascribed to multiple causes. Specifically, the modified Duke clinical diagnosis criteria incorporated more items, including clinical findings, microbiological analysis, imaging results, and available pathological specimen detections, and prosthetic valve endocarditis and cardiac device infection were also considered in IE diagnosis[8; 24], which enlarged the spectrum of disease inclusion. Moreover, the improved methods of detection in GBD, population ageing, the increase in pathogenic bacteria and mushrooming employment of cardiac indwelling electronic devices (CIEDs) as medical technology progresses are likewise contributors to the increase in IE incidence.

Several important changes were identified in this study, including a significantly increased rate of IE in males and those of older age. In line with previous studies[25; 26], we observed that IE predominantly affected elderly individuals (aged above 50 years old), which demonstrated the potential influence of age on IE morbidity. We speculated that elderly individuals were more likely to suffer from nosocomial IE due to the greater requirements for invasive procedures. Furthermore, we found higher ASRs of incidence, death and DALY, and faster increase in EAPC of ASIR and ASDR, as well as slower decrease in EAPC of DALY in males during the past thirty years, which all demonstrated graver insults of IE in male health to some extent without the exact reason reported yet. 
The geographical difference in IE morbidity remains obvious based on the division of socioeconomic status. The positive correlation between ASIR and SDI suggested that ASIR seemed to be higher in relatively developed regions. In recent decades, there have been huge changes in IE risk factors[3] which may result in epidemic differences among various SDI regions. The latest review on The Lancet[8] listed core cardiac risk factors and noncardiac risk factors, including rheumatic heart disease (RHD), prosthetic valve (PVE), intravenous drug use (IDU), CIED and others. Approximately $50 \%$ of these IE cases were health-care associated (HCA-IE) and constantly increased, especially for nosocomial IE, including IDU-IE, PVE-IE and CIED-IE, in America[27; 28; 29]. A similar trend could be seen in other developed countries, such as Spain, Germany and Italy[30; $31 ; 32]$. The reason why the potential pathogenic contributors to IE changed so much might be the in-mounting burden due to drugs and population ageing in countries with higher SDI levels[33]. For developing countries, RHD accounts for up to two-thirds of IE cases[34], even if developed countries have achieved the near elimination of acute rheumatic fever and a reduction in the rates of rheumatic heart disease during the late 20th century[35]. Since RHD is a postinfection inflammation often attacking children and adolescents[36], the rate of community-acquired IE in low-SDI countries is higher, and the patients are younger. In addition, we concluded that the EAPC of the ASIR and SDI are positively correlated, which means that the influence of newly emerging disease patterns in developed countries is great and that the incidence of IE may be higher with the development of the global economy. The lowest EAPC of ASIR in the low SDI region may be attributed to the constant decline in RHD burden globally.

Globally, the deaths due to IE were substantially mounting in 2019, especially for high SDI regions. Intractable bacteria such as Staphylococcus aureus (S aureus) instead of viridans group streptococci (VGS) were considered the predominant pathogens for IE by degrees[25; 37]. Unfortunately,

S. aureus has a notorious propensity to acquire antibiotic resistance, and meticillin-resistant strains have emerged worldwide[38], which contributes to poor prognosis and high mortality. The susceptibility to $\mathrm{S}$ aureus is mainly attributed to the altered causative constitution of IE, including a growing body of HCA-IE patients affected by $S$ aureus after experiencing invasive procedures[39; 40], immunosuppressive patients with long-term IDU or suffering from carcinoma and diabetes, and population ageing, especially in developed regions. Moreover, despite a certain increase in deaths in low-income regions, the ASDR and EAPC of ASDR presented obvious shrinkage, which was predominantly ascribed to improved medical treatment for RHD in these regions. We also found a positive association between EAPC of ASDR and SDI, meaning that the regions with higher SDI had a more distinctive change in ASDR of IE, which was partly related to the contributing factors mentioned above.

In our paper, we showed that the global trend of IE age-standardized DALYs was declining despite variances among countries and regions. Considering that the factors possibly contributing to IE incidence and mortality were mainly nosocomial, such as IDU, PVE and CIED, we ascribed the decreasing DALYs partly to the progress in health care and medical technology, which obviously promoted better IE diagnosis and therapy, improved patients' quality of life, and lessened IE DALYs. Especially in relatively developed regions, there are advanced medical levels despite higher IE incidence. As expected, the correlation analysis revealed a negative association between the age-standardized DALY rate and SDI. Furthermore, there was an obvious positive correlation between the EAPC of age-standardized DALY rates and the SDI in 2019, which demonstrated that the higher the SDI was, the greater the change in age-standardized DALY rates was.

There remain some limitations in the current study. The methods of the GBD presented potential biases on our estimates in the current article, as with all GBD research. First, the limited availability and quality of surveillance data from high-burden countries was an important limitation. Moreover, the missed diagnosis and misdiagnosis in clinical practice owing to the complexity of IE increased the underreported cases. Finally, analysis according to the clinical classification of IE requires more studies to better understand the epidemiology of IE.

In summary, the overall burden of infective endocarditis is staggering and continues to increase annually, and the incidence, mortality and disability-adjusted life years present substantial heterogeneity in different genders, ages and regions. The current study may provide a vital reference for policy-makers and clinical scientists to respond to IE and formulate more effective interventional measures.

\section{Declarations}

\section{Conflict of Interest}

The authors declare no conflicts of interest.

\section{Author Contributions}

ZLZ had full access to the data in the study and take responsibility for the integrity of the data and the accuracy of the data analysis. All authors approved the final manuscript. Concept and design: ZLZ and HLC. Acquisition, analysis and interpretation of data: YZ, ZRC, KMZ, YPG, LYC and JZ. Drafting of the manuscript: HLC, YZ and ZRC. Revision of the manuscript: ZLZ and HLC. Statistical analysis: HLC and YZ; Supervision: ZLZ and HLC.

\section{Funding}

This work was funded by National Natural Science Foundation of China (No. 81800041 and 82000078 ).

\section{Acknowledgments}

We are grateful to all staffs of the Global Burden of Disease Study for their work. 


\section{Data Availability Statement}

The datasets used in the present study are available in GBD 2019.

\section{References}

[1] A. Wang, J.G. Gaca, and V.H. Chu, Management Considerations in Infective Endocarditis: A Review. JAMA 320 (2018) 72-83.

[2] R.A. Nishimura, C.M. Otto, R.O. Bonow, B.A. Carabello, J.P. Erwin, 3rd, R.A. Guyton, P.T. O'Gara, C.E. Ruiz, N.J. Skubas, P. Sorajja, T.M. Sundt, 3rd, J.D. Thomas, and G. American College of Cardiology/American Heart Association Task Force on Practice, 2014 AHA/ACC guideline for the management of patients with valvular heart disease: a report of the American College of Cardiology/American Heart Association Task Force on Practice Guidelines. J Am Coll Cardiol 63 (2014) e57-185.

[3] J. Ambrosioni, M. Hernandez-Meneses, A. Tellez, J. Pericas, C. Falces, J.M. Tolosana, B. Vidal, M. Almela, E. Quintana, J. Llopis, A. Moreno, J.M. Miro, and I. Hospital Clinic Infective Endocarditis, The Changing Epidemiology of Infective Endocarditis in the Twenty-First Century. Curr Infect Dis Rep 19 (2017) 21.

[4] C. Selton-Suty, M. Celard, V. Le Moing, T. Doco-Lecompte, C. Chirouze, B. lung, C. Strady, M. Revest, F. Vandenesch, A. Bouvet, F. Delahaye, F. Alla, X. Duval, B. Hoen, and A.S. Group, Preeminence of Staphylococcus aureus in infective endocarditis: a 1-year population-based survey. Clin Infect Dis 54 (2012) $1230-9$.

[5] B. Hajihossainlou, M.A. Heidarnia, and B. Sharif Kashani, Changing pattern of infective endocarditis in Iran: A 16 years survey. Pak J Med Sci 29 (2013) 8590 .

[6] M. Alkhouli, F. Alqahtani, M. Alhajji, C.O. Berzingi, and M.R. Sohail, Clinical and Economic Burden of Hospitalizations for Infective Endocarditis in the United States. Mayo Clin Proc 95 (2020) 858-866.

[7] A. Wang, The changing epidemiology of infective endocarditis: the paradox of prophylaxis in the current and future eras. J Am Coll Cardiol 59 (2012) 19778.

[8] T.J. Cahill, B.D. Prendergast, Infective endocarditis. Lancet 387,10021 (2016): 882-93.

[9] S.A. Hubers, D.C. DeSimone, B.J. Gersh, and N.S. Anavekar, Infective Endocarditis: A Contemporary Review. Mayo Clin Proc 95 (2020) $982-997$.

[10] B.D. Prendergast, The changing face of infective endocarditis. Heart 92 (2006) 879-85.

[11] G. Habib, P. Lancellotti, M.J. Antunes, M.G. Bongiorni, J.P. Casalta, F. Del Zotti, R. Dulgheru, G. El Khoury, P.A. Erba, B. lung, J.M. Miro, B.J. Mulder, E. Plonska-Gosciniak, S. Price, J. Roos-Hesselink, U. Snygg-Martin, F. Thuny, P. Tornos Mas, I. Vilacosta, J.L. Zamorano, and E.S.C.S.D. Group, 2015 ESC Guidelines for the management of infective endocarditis: The Task Force for the Management of Infective Endocarditis of the European Society of Cardiology (ESC). Endorsed by: European Association for Cardio-Thoracic Surgery (EACTS), the European Association of Nuclear Medicine (EANM). Eur Heart J 36 (2015) 3075-3128.

[12] L. Saby, O. Laas, G. Habib, S. Cammilleri, J. Mancini, L. Tessonnier, J.P. Casalta, F. Gouriet, A. Riberi, J.F. Avierinos, F. Collart, O. Mundler, D. Raoult, and F. Thuny, Positron emission tomography/computed tomography for diagnosis of prosthetic valve endocarditis: increased valvular 18F-fluorodeoxyglucose uptake as a novel major criterion. J Am Coll Cardiol 61 (2013) 2374-82.

[13] F. Chirillo, P. Scotton, F. Rocco, R. Rigoli, F. Borsatto, A. Pedrocco, A. De Leo, G. Minniti, E. Polesel, and Z. Olivari, Impact of a multidisciplinary management strategy on the outcome of patients with native valve infective endocarditis. Am J Cardiol 112 (2013) 1171-6.

[14] G.B.D. Diseases, and C. Injuries, Global burden of 369 diseases and injuries in 204 countries and territories, 1990-2019: a systematic analysis for the Global Burden of Disease Study 2019. Lancet 396 (2020) 1204-1222.

[15] C.J. Murray, M. Ezzati, A.D. Flaxman, S. Lim, R. Lozano, C. Michaud, M. Naghavi, J.A. Salomon, K. Shibuya, T. Vos, D. Wikler, and A.D. Lopez, GBD 2010: design, definitions, and metrics. Lancet 380 (2012) 2063-6.

[16] A.A. Bin Abdulhak, L.M. Baddour, P.J. Erwin, B. Hoen, V.H. Chu, G.A. Mensah, and I.M. Tleyjeh, Global and regional burden of infective endocarditis, 19902010: a systematic review of the literature. Glob Heart 9 (2014) 131-43.

[17] D.Y. Zeng, J.M. Li, S. Lin, X. Dong, J. You, Q.Q. Xing, Y.D. Ren, W.M. Chen, Y.Y. Cai, K. Fang, M.Z. Hong, Y. Zhu, and J.S. Pan, Global burden of acute viral hepatitis and its association with socioeconomic development status, 1990-2019. J Hepatol (2021).

[18] X. Yang, J. Man, H. Chen, T. Zhang, X. Yin, Q. He, and M. Lu, Temporal trends of the lung cancer mortality attributable to smoking from 1990 to 2017: A global, regional and national analysis. Lung Cancer 152 (2021) 49-57.

[19] J. Fan, Z. Liu, X. Mao, X. Tong, T. Zhang, C. Suo, and X. Chen, Global trends in the incidence and mortality of esophageal cancer from 1990 to 2017. Cancer Med 9 (2020) 6875-6887.

[20] Y. Deng, H. Li, M. Wang, N. Li, T. Tian, Y. Wu, P. Xu, S. Yang, Z. Zhai, L. Zhou, Q. Hao, D. Song, T. Jin, J. Lyu, and Z. Dai, Global Burden of Thyroid Cancer From 1990 to 2017. JAMA Netw Open 3 (2020) e208759. 
[21] G.B.D.N. Collaborators, Global, regional, and national burden of neurological disorders, 1990-2016: a systematic analysis for the Global Burden of Disease Study 2016. Lancet Neurol 18 (2019) 459-480.

[22] S. Pant, N.J. Patel, A. Deshmukh, H. Golwala, N. Patel, A. Badheka, G.A. Hirsch, and J.L. Mehta, Trends in infective endocarditis incidence, microbiology, and valve replacement in the United States from 2000 to 2011. J Am Coll Cardiol 65 (2015) 2070-6.

[23] A.S. Mackie, W. Liu, A. Savu, A.J. Marelli, P. Kaul, Infective Endocarditis Hospitalizations Before and After the 2007 American Heart Association Prophylaxis Guidelines. Can J Cardiol 32,8 (2016): 942-8.

[24] J.S. Li, D.J. Sexton, N. Mick, R. Nettles, V.G. Fowler, T. Jr. Ryan, T. Bashore, G.R. Corey, Proposed modifications to the Duke criteria for the diagnosis of infective endocarditis. Clin Infect Dis 30,4 (2000): 633-8.

[25] D.C. DeSimone, I.M. Tleyjeh, D.D. Correa de Sa, N.S. Anavekar, B.D. Lahr, M.R. Sohail, J.M. Steckelberg, W.R. Wilson, and L.M. Baddour, Temporal trends in infective endocarditis epidemiology from 2007 to 2013 in Olmsted County, MN. Am Heart J 170 (2015) 830-6.

[26] I.M. Tleyjeh, J.M. Steckelberg, H.S. Murad, N.S. Anavekar, H.M. Ghomrawi, Z. Mirzoyev, S.E. Moustafa, T.L. Hoskin, J.N. Mandrekar, W.R. Wilson, and L.M. Baddour, Temporal trends in infective endocarditis: a population-based study in Olmsted County, Minnesota. JAMA 293 (2005) $3022-8$.

[27] N. Toyoda, J. Chikwe, S. Itagaki, A.C. Gelijns, D.H. Adams, and N.N. Egorova, Trends in Infective Endocarditis in California and New York State, $1998-2013$. JAMA 317 (2017) 1652-1660.

[28] A.G. Wurcel, J.E. Anderson, K.K. Chui, S. Skinner, T.A. Knox, D.R. Snydman, and T.J. Stopka, Increasing Infectious Endocarditis Admissions Among Young People Who Inject Drugs. Open Forum Infect Dis 3 (2016) ofw157.

[29] D.H. Bor, S. Woolhandler, R. Nardin, J. Brusch, and D.U. Himmelstein, Infective endocarditis in the U.S., 1998-2009: a nationwide study. PLoS One 8 (2013) e60033.

[30] C. Olmos, I. Vilacosta, C. Fernandez-Perez, J.L. Bernal, C. Ferrera, D. Garcia-Arribas, C.N. Perez-Garcia, J.A. San Roman, L. Maroto, C. Macaya, and F.J. Elola, The Evolving Nature of Infective Endocarditis in Spain: A Population-Based Study (2003 to 2014). J Am Coll Cardiol 70 (2017) $2795-2804$.

[31] K. Keller, R.S. von Bardeleben, M.A. Ostad, L. Hobohm, T. Munzel, S. Konstantinides, and M. Lankeit, Temporal Trends in the Prevalence of Infective Endocarditis in Germany Between 2005 and 2014. Am J Cardiol 119 (2017) 317-322.

[32] A. Cresti, M. Chiavarelli, M. Scalese, C. Nencioni, S. Valentini, F. Guerrini, I. D'Aiello, A. Picchi, F. De Sensi, and G. Habib, Epidemiological and mortality trends in infective endocarditis, a 17-year population-based prospective study. Cardiovasc Diagn Ther 7 (2017) 27-35.

[33] GBD 2016 Alcohol and Drug Use Collaborators, The global burden of disease attributable to alcohol and drug use in 195 countries and territories, 1990 2016: a systematic analysis for the Global Burden of Disease Study 2016. The lancet Psychiatry 5,12 (2018): 987-1012.

[34] J.R. Carapetis, A.C. Steer, E.K. Mulholland, and M. Weber, The global burden of group A streptococcal diseases. Lancet Infect Dis 5 (2005) 685-94.

[35] D.A. Watkins, C.O. Johnson, S.M. Colquhoun, G. Karthikeyan, A. Beaton, G. Bukhman, M.H. Forouzanfar, C.T. Longenecker, B.M. Mayosi, G.A. Mensah, B.R. Nascimento, A.L.P. Ribeiro, C.A. Sable, A.C. Steer, M. Naghavi, A.H. Mokdad, C.J.L. Murray, T. Vos, J.R. Carapetis, and G.A. Roth, Global, Regional, and National Burden of Rheumatic Heart Disease, 1990-2015. N Engl J Med 377 (2017) 713-722.

[36] E. Marijon, M. Mirabel, D.S. Celermajer, and X. Jouven, Rheumatic heart disease. The Lancet 379 (2012) 953-964.

[37] D.D. Correa de Sa, I.M. Tleyjeh, N.S. Anavekar, J.C. Schultz, J.M. Thomas, B.D. Lahr, A. Bachuwar, M. Pazdernik, J.M. Steckelberg, W.R. Wilson, and L.M. Baddour, Epidemiological trends of infective endocarditis: a population-based study in Olmsted County, Minnesota. Mayo Clin Proc 85 (2010) $422-6$.

[38] R.A. Weinstein, J.S. Molton, P.A. Tambyah, B.S.P. Ang, M.L. Ling, and D.A. Fisher, The Global Spread of Healthcare-Associated Multidrug-Resistant Bacteria: A Perspective From Asia. Clinical Infectious Diseases 56 (2013) 1310-1318.

[39] D. Pittet, and R.P. Wenzel, Nosocomial bloodstream infections. Secular trends in rates, mortality, and contribution to total hospital deaths. Arch Intern Med 155 (1995) 1177-84.

[40] H.S. Ammerlaan, S. Harbarth, A.G. Buiting, D.W. Crook, F. Fitzpatrick, H. Hanberger, L.A. Herwaldt, P.H. van Keulen, J.A. Kluytmans, A. Kola, R.S. Kuchenbecker, E. Lingaas, N. Meessen, M.M. Morris-Downes, J.M. Pottinger, P. Rohner, R.P. dos Santos, H. Seifert, H. Wisplinghoff, S. Ziesing, A.S. Walker, and M.J. Bonten, Secular trends in nosocomial bloodstream infections: antibiotic-resistant bacteria increase the total burden of infection. Clin Infect Dis 56 (2013) 798-805.

\section{Tables}


Table 1. The incidence of infective endocarditis in 1990/2019 and temporal trends

\begin{tabular}{|c|c|c|c|c|c|}
\hline \multirow[t]{2}{*}{ Characteristics } & \multicolumn{3}{|l|}{1990} & \multicolumn{2}{|l|}{2019} \\
\hline & $\begin{array}{l}\text { Incident cases } \\
\text { No } \times 10^{3}(95 \% \mathrm{Cl})\end{array}$ & & $\begin{array}{l}\text { ASIR/ } 10^{5} \\
\text { No. }(95 \% \mathrm{CI})\end{array}$ & $\begin{array}{l}\text { Incident cases } \\
\text { No } \times 10^{3}(95 \% \mathrm{Cl})\end{array}$ & $\begin{array}{l}\text { ASIR/ } 10^{5} \\
\text { No. }(95 \% \mathrm{CI})\end{array}$ \\
\hline Overall & 478.00(393.39 572.42) & $9.91(8.24 \sim 11.84)$ & 1090.53(913.50 1296.29) & 13.80(11.59 16.34) & $1.2(1.16 \sim 1.24)$ \\
\hline \multicolumn{6}{|l|}{ Sex } \\
\hline Female & $217.20(178.42 \sim 262.26)$ & 8.84(7.31 10.63) & 480.43(401.56 575.14) & 11.62(9.67 13.83) & $0.96(0.93 \sim 1)$ \\
\hline
\end{tabular}

Socio-
demographic
factor

factor

\begin{tabular}{clllll} 
High SDI & $100.54(83.61 \sim 121.96)$ & $11.01(9.14 \sim 13.37)$ & $251.57(215.00 \sim 296.06)$ & $15.85(13.56 \sim 18.53)$ & $1.25(1.09 \sim 1.41)$ \\
$\begin{array}{c}\text { High-middle } \\
\text { SDI }\end{array}$ & $124.76(102.74 \sim 150.52)$ & $11.34(9.44 \sim 13.59)$ & $283.71(235.85 \sim 341.81)$ & $15.86(13.24 \sim 18.93)$ & $1.26(1.21 \sim 1.31)$ \\
Middle SDI & $159.20(130.20 \sim 191.00)$ & $10.50(8.75 \sim 12.50)$ & $314.02(260.10 \sim 379.41)$ & $13.22(11.01 \sim 15.77)$ & $0.99(0.89 \sim 1.09)$ \\
\hline $\begin{array}{c}\text { Low-middle } \\
\text { SDI }\end{array}$ & $62.64(50.33 \sim 76.48)$ & $6.47(5.31 \sim 7.78)$ & $144.05(117.96 \sim 174.20)$ & $9.33(7.79 \sim 11.16)$ & $1.31(1.19 \sim 1.43)$ \\
\hline Low SDI & $30.59(24.43 \sim 38.07)$ & $6.29(5.23 \sim 7.50)$ & $72.75(58.02 \sim 89.54)$ & $7.39(6.13 \sim 8.809)$ & $0.81(0.65 \sim 0.97)$
\end{tabular}

Region

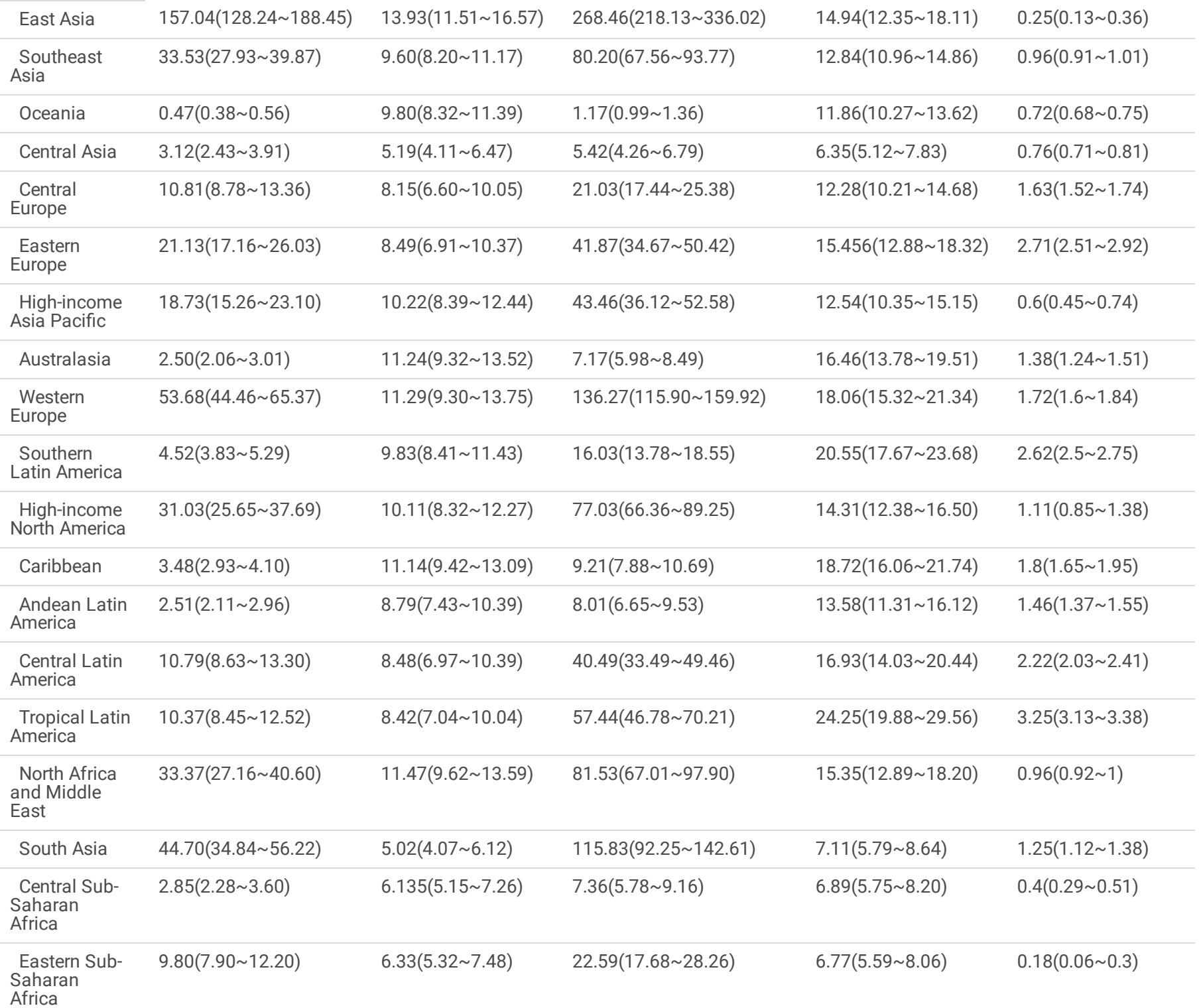




\begin{tabular}{|c|c|c|c|c|c|}
\hline $\begin{array}{l}\text { Southern } \\
\text { Sub-Saharan } \\
\text { Africa }\end{array}$ & $3.49(2.80 \sim 4.24)$ & 7.83(6.52 9.28) & $5.69(4.59 \sim 6.91)$ & $8.09(6.65 \sim 9.70)$ & $-0.12(-0.22 \sim-0.02)$ \\
\hline $\begin{array}{l}\text { Western Sub- } \\
\text { Saharan } \\
\text { Africa }\end{array}$ & $20.07(15.87 \sim 25.04)$ & & $9.25(7.71 \sim 10.95)$ & & $44.28(35.15 \sim 55.81)$ \\
\hline
\end{tabular}

Note: ASIR, age-standardized incident rate per 100000 population; SDI, social-demographic index; EAPC, estimated annual percentage change. 
Table 2. The death of infective endocarditis in 1990/2019 and temporal trends

\begin{tabular}{llllll} 
Characteristics & 1990 & \multicolumn{5}{c}{2019} & \\
\cline { 2 - 6 } & $\begin{array}{l}\text { Death } \\
\text { Nox } 10^{3}(95 \% \mathrm{Cl})\end{array}$ & $\begin{array}{l}\text { ASDR/10 } \\
\text { No. }(95 \% \mathrm{Cl})\end{array}$ & $\begin{array}{l}\text { Death } \\
\text { Nox } 10^{3}(95 \% \mathrm{Cl})\end{array}$ & $\begin{array}{l}\text { ASDR/10 } \\
\text { No. }(95 \% \mathrm{Cl})\end{array}$ & $\begin{array}{l}\text { EAPC } \\
\text { No. }(95 \% \mathrm{Cl})\end{array}$ \\
\hline Overall & $28.75(24.37 \sim 35.7)$ & $0.73(0.63 \sim 0.93)$ & $66.32(46.21 \sim 75.86)$ & $0.87(0.59 \sim 1)$ & $0.71(0.44 \sim 0.98)$ \\
\hline Sex & & & & & \\
Male & $14.72(12.06 \sim 18.7)$ & $0.77(0.65 \sim 1.02)$ & $32.63(22.3 \sim 37.64)$ & $0.94(0.62 \sim 1.09)$ & $0.79(0.57 \sim 1.01)$ \\
\hline Female & $14.03(10.94 \sim 18.81)$ & $0.66(0.53 \sim 0.91)$ & $33.69(21.43 \sim 39.18)$ & $0.78(0.5 \sim 0.91)$ & $0.66(0.35 \sim 0.96)$
\end{tabular}

Socio-

demographic

factor

$\begin{array}{clllll}\text { High SDI } & 7.19(5.9 \sim 11.49) & 0.71(0.58 \sim 1.12) & 24.68(11.73 \sim 30.81) & 1.16(0.58 \sim 1.43) & 2.01(1.51 \sim 2.51) \\ \begin{array}{c}\text { High-middle } \\ \text { SDI }\end{array} & 5.94(4.99 \sim 7.71) & 0.6(0.5 \sim 0.78) & 13.26(9.19 \sim 15.08) & 0.71(0.49 \sim 0.8) & 0.62(0.38 \sim 0.86) \\ \text { Middle SDI } & 8(6.54 \sim 9.53) & 0.69(0.56 \sim 0.84) & 14.07(12.02 \sim 17.64) & 0.62(0.52 \sim 0.77) & -0.62(-0.76 \sim-0.48) \\ \begin{array}{c}\text { Low-middle } \\ \text { SDI }\end{array} & 4.64(3.5 \sim 5.48) & 0.66(0.52 \sim 0.78) & 9.19(7.49 \sim 11.1) & 0.67(0.55 \sim 0.82) & -0.06(-0.13 \sim 0.01) \\ \text { Low SDI } & 2.96(1.83 \sim 4.07) & 0.9(0.55 \sim 1.38) & 5.07(3.72 \sim 6.61) & 0.79(0.55 \sim 1.06) & -0.56(-0.64 \sim-0.48)\end{array}$

Region

\begin{tabular}{|c|c|c|c|c|c|}
\hline East Asia & 4.36(2.73 5.34) & $0.48(0.31 \sim 0.58)$ & 4.91(3.75 5.83) & $0.29(0.21 \sim 0.34)$ & $-2.4(-2.78 \sim-2.02)$ \\
\hline $\begin{array}{l}\text { Southeast } \\
\text { Asia }\end{array}$ & $3.54(2.83 \sim 4.91)$ & 1.22(0.97 1.69) & 7.48(6.03 10.35) & $1.29(1.04 \sim 1.76)$ & $0(-0.16 \sim 0.16)$ \\
\hline Oceania & $0.04(0.02 \sim 0.06)$ & $1.25(0.78 \sim 2.25)$ & $0.12(0.08 \sim 0.16)$ & 1.64(1.13 2.26) & 1.24(1.11 1.37) \\
\hline Central Asia & $0.1(0.08 \sim 0.13)$ & $0.21(0.16 \sim 0.27)$ & $0.24(0.2 \sim 0.32)$ & $0.33(0.28 \sim 0.44)$ & $1.69(1.44 \sim 1.94)$ \\
\hline $\begin{array}{l}\text { Central } \\
\text { Europe }\end{array}$ & $0.47(0.41 \sim 0.69)$ & $0.34(0.3 \sim 0.5)$ & $0.93(0.56 \sim 1.14)$ & $0.48(0.28 \sim 0.59)$ & $1.39(1.15 \sim 1.63)$ \\
\hline $\begin{array}{l}\text { Eastern } \\
\text { Europe }\end{array}$ & 1.01(0.77 1.83) & $0.39(0.3 \sim 0.7)$ & 2.19(1.59 2.64) & $0.78(0.56 \sim 0.95)$ & $2.44(2.05 \sim 2.83)$ \\
\hline $\begin{array}{l}\text { High-income } \\
\text { Asia Pacific }\end{array}$ & 1.37(0.93 1.6) & $0.79(0.53 \sim 0.92)$ & $4.42(1.82 \sim 5.96)$ & $0.75(0.36 \sim 0.97)$ & $-0.69(-1.09 \sim-0.28)$ \\
\hline Australasia & $0.12(0.1 \sim 0.18)$ & $0.54(0.46 \sim 0.79)$ & $0.43(0.2 \sim 0.56)$ & $0.82(0.39 \sim 1.04)$ & $1.71(1.38 \sim 2.04)$ \\
\hline $\begin{array}{l}\text { Western } \\
\text { Europe }\end{array}$ & 4.12(3.15 7.55) & $0.72(0.56 \sim 1.3)$ & $13.79(6.58 \sim 17.12)$ & $1.28(0.63 \sim 1.57)$ & $2.59(2.15 \sim 3.03)$ \\
\hline $\begin{array}{l}\text { Southern } \\
\text { Latin America }\end{array}$ & $0.59(0.41 \sim 0.75)$ & 1.38(0.94 1.77) & $1.53(1.18 \sim 1.8)$ & 1.84(1.42 2.16) & $0.78(0.48 \sim 1.07)$ \\
\hline $\begin{array}{l}\text { High-income } \\
\text { North America }\end{array}$ & 2.14(1.63 3.84) & $0.61(0.46 \sim 1.08)$ & 8.98(4.33 11.04) & $1.36(0.68 \sim 1.65)$ & $3.26(2.43 \sim 4.09)$ \\
\hline Caribbean & $0.22(0.18 \sim 0.29)$ & $0.75(0.65 \sim 0.97)$ & $0.44(0.35 \sim 0.54)$ & $0.88(0.71 \sim 1.08)$ & $0.75(0.69 \sim 0.81)$ \\
\hline $\begin{array}{l}\text { Andean Latin } \\
\text { America }\end{array}$ & $0.22(0.16 \sim 0.28)$ & $0.8(0.59 \sim 0.94)$ & $0.33(0.25 \sim 0.43)$ & $0.59(0.44 \sim 0.76)$ & $-1.11(-1.18 \sim-1.03)$ \\
\hline $\begin{array}{l}\text { Central Latin } \\
\text { America }\end{array}$ & $0.43(0.38 \sim 0.61)$ & $0.4(0.35 \sim 0.58)$ & $1.29(0.89 \sim 1.58)$ & $0.54(0.38 \sim 0.67)$ & $1.15(0.92 \sim 1.38)$ \\
\hline $\begin{array}{l}\text { Tropical Latin } \\
\text { America }\end{array}$ & $0.94(0.8 \sim 1.47)$ & $0.82(0.7 \sim 1.35)$ & 2.51(1.77 2.82) & 1.06(0.74 1.19) & $1.04(0.78 \sim 1.3)$ \\
\hline $\begin{array}{l}\text { North Africa } \\
\text { and Middle } \\
\text { East }\end{array}$ & $1.73(1.25 \sim 2.12)$ & $0.83(0.64 \sim 0.99)$ & $2.74(2.07 \sim 3.29)$ & $0.65(0.51 \sim 0.79)$ & $-0.85(-0.92 \sim-0.78)$ \\
\hline South Asia & $3.79(2.95 \sim 4.77)$ & $0.64(0.51 \sim 0.79)$ & 8.77(6.93 10.89) & $0.64(0.51 \sim 0.8)$ & $-0.12(-0.2 \sim-0.04)$ \\
\hline $\begin{array}{l}\text { Central Sub- } \\
\text { Saharan } \\
\text { Africa }\end{array}$ & $0.32(0.18 \sim 0.51)$ & 1.17(0.58 2.03) & $0.61(0.35 \sim 0.97)$ & $1.02(0.56 \sim 1.68)$ & $-0.58(-0.65 \sim-0.51)$ \\
\hline $\begin{array}{l}\text { Eastern Sub- } \\
\text { Saharan } \\
\text { Africa }\end{array}$ & $1.13(0.61 \sim 1.81)$ & $1.14(0.55 \sim 2.05)$ & 1.83(1.07 2.89) & $0.91(0.5 \sim 1.49)$ & $-0.9(-1 \sim-0.8)$ \\
\hline Southern & $0.37(0.25 \sim 0.44)$ & $1.01(0.7 \sim 1.2)$ & $0.48(0.39 \sim 0.61)$ & $0.79(0.65 \sim 1)$ & $-1.11(-1.5 \sim-0.71)$ \\
\hline
\end{tabular}


Sub-Saharan

Africa

Western Sub-

1.74(0.91 2.45)

1.2(0.73 1.76)

$2.29(1.76 \sim 3.05)$

$0.78(0.61 \sim 1.02)$

$-1.77$

Africa

Note: ASDR, age-standardized death rate per 100000 population; SDI, social-demographic index; EAPC, estimated annual percentage change. 
Table 3. The DALYs of infective endocarditis in 1990/2019 and temporal trends

Characteristics 199

2019

\section{DALYS}

$\operatorname{No} \times 10^{3}(95 \% \mathrm{Cl})$
Age standardized

DALYs $/ 10^{5}$

No. $(95 \% \mathrm{Cl})$
DALYS

No $\times 10^{3}(95 \% \mathrm{Cl})$

\begin{tabular}{|c|c|c|c|c|c|}
\hline Overall & 1118.12(836.79 1318.66) & 22.78(17.98 26.97) & $1723.59(1355.67 \sim 1935.25)$ & 21.93(17.17 24.6) & $-0.21(-0.35 \sim-0.08)$ \\
\hline \multicolumn{6}{|l|}{ Sex } \\
\hline Male & 617.35(463.03 749.04) & 25.41(20.09 31.37) & $972.61(735.86 \sim 1123.53)$ & 25.46(19.06 29.12) & $-0.05(-0.18 \sim 0.07)$ \\
\hline Female & $500.77(319.04 \sim 627.69)$ & 20(13.53 25.53) & 750.98(536.88 870.75) & $18.33(13.23 \sim 21.33)$ & $-0.41(-0.56 \sim-0.25)$ \\
\hline \multicolumn{6}{|l|}{$\begin{array}{l}\text { Socio- } \\
\text { demographic } \\
\text { factor }\end{array}$} \\
\hline High SDI & 157.8(131.72 234.56) & 16.27(13.51 24) & $386.32(212.21 \sim 461.4)$ & 22.33(12.61 26.23) & $1.32(0.95 \sim 1.7)$ \\
\hline $\begin{array}{l}\text { High-middle } \\
\text { SDI }\end{array}$ & 213.6(170.09 253.17) & $19.46(15.45 \sim 23.03)$ & $325.01(238.95 \sim 365.72)$ & 18.38(13.65 20.7) & $-0.42(-0.62 \sim-0.23)$ \\
\hline Middle SDI & $379.69(280.63 \sim 449.48)$ & 24.34(19.13 28.65) & 454.53(390.82 582.66) & 18.55(15.94 23.45) & $-1.2(-1.34 \sim-1.07)$ \\
\hline $\begin{array}{l}\text { Low-middle } \\
\text { SDI }\end{array}$ & 212.42(138.86 271.28) & $21.77(16.16 \sim 25.98)$ & $325.38(262.88 \sim 395.76)$ & 20.48(16.51 24.91) & $-0.32(-0.39 \sim-0.25)$ \\
\hline Low SDI & 153.84(79.37 223.34) & 31.18(19.43 43.54) & 230.95(173.53 299.55) & 25.3(18.62 32.83) & $-0.82(-0.92 \sim-0.72)$ \\
\hline \multicolumn{6}{|l|}{ Region } \\
\hline East Asia & 225.16(123.24 291.15) & $0.48(0.31 \sim 0.58)$ & 127.6(100.95 153.97) & $0.29(0.21 \sim 0.34)$ & $-4.4(-4.91 \sim-3.88)$ \\
\hline $\begin{array}{l}\text { Southeast } \\
\text { Asia }\end{array}$ & 151.03(122.05 217.56) & 1.22(0.97 1.69) & 255.83(208.03 359.59) & $1.29(1.04 \sim 1.76)$ & $-0.26(-0.46 \sim-0.06)$ \\
\hline Oceania & $1.55(1.03 \sim 2.38)$ & $1.25(0.78 \sim 2.25)$ & $4.61(3.1 \sim 6.41)$ & $1.64(1.13 \sim 2.26)$ & $1.26(1.13 \sim 1.4)$ \\
\hline Central Asia & $3.77(3.06 \sim 4.52)$ & $0.21(0.16 \sim 0.27)$ & $8.27(6.95 \sim 11.3)$ & $0.33(0.28 \sim 0.44)$ & $1.35(1.05 \sim 1.65)$ \\
\hline $\begin{array}{l}\text { Central } \\
\text { Europe }\end{array}$ & 14.36(12.75 20.56) & $0.34(0.3 \sim 0.5)$ & 23.26(13.6 29.04) & $0.48(0.28 \sim 0.59)$ & 1.16(0.94 1.38) \\
\hline $\begin{array}{l}\text { Eastern } \\
\text { Europe }\end{array}$ & $35.68(27.36 \sim 65.37)$ & $0.39(0.3 \sim 0.7)$ & 79.48(53.86 97.14) & $0.78(0.56 \sim 0.95)$ & $2.81(2.35 \sim 3.27)$ \\
\hline $\begin{array}{l}\text { High-income } \\
\text { Asia Pacific }\end{array}$ & 33.18(22.99 38.31) & $0.79(0.53 \sim 0.92)$ & $56.07(30.42 \sim 69.53)$ & $0.75(0.36 \sim 0.97)$ & $-1.72(-1.99 \sim-1.44)$ \\
\hline Australasia & $2.93(2.53 \sim 4.18)$ & $0.54(0.46 \sim 0.79)$ & 7.44(3.85 9.11) & $0.82(0.39 \sim 1.04)$ & $1.05(0.8 \sim 1.3)$ \\
\hline $\begin{array}{l}\text { Western } \\
\text { Europe }\end{array}$ & 77.71(61.59 135.36) & $0.72(0.56 \sim 1.3)$ & 193.13(100.18 232.92) & $1.28(0.63 \sim 1.57)$ & 1.91(1.51 2.32) \\
\hline $\begin{array}{l}\text { Southern } \\
\text { Latin America }\end{array}$ & 14.77(11.08 19.2) & 1.38(0.94 1.77) & $31.78(25.79 \sim 39.14)$ & 1.84(1.42 2.16) & $0.58(0.34 \sim 0.83)$ \\
\hline $\begin{array}{l}\text { High-income } \\
\text { North America }\end{array}$ & $49.8(40.43 \sim 82.72)$ & $0.61(0.46 \sim 1.08)$ & 159.45(85.9 187.88) & 1.36(0.68 1.65) & $2.66(2.01 \sim 3.32)$ \\
\hline Caribbean & 9.71(7.34 14.09) & $0.75(0.65 \sim 0.97)$ & 15.38(11.98 19.67) & $0.88(0.71 \sim 1.08)$ & $0.54(0.47 \sim 0.61)$ \\
\hline $\begin{array}{l}\text { Andean Latin } \\
\text { America }\end{array}$ & 11.56(7.57 15.8) & $0.8(0.59 \sim 0.94)$ & 11.27(8.61 14.62) & $0.59(0.44 \sim 0.76)$ & $-1.8(-1.88 \sim-1.72)$ \\
\hline $\begin{array}{l}\text { Central Latin } \\
\text { America }\end{array}$ & 20.35(17.53 27.1) & $0.4(0.35 \sim 0.58)$ & $42.52(29.45 \sim 52.97)$ & $0.54(0.38 \sim 0.67)$ & $0.9(0.68 \sim 1.12)$ \\
\hline $\begin{array}{l}\text { Tropical Latin } \\
\text { America }\end{array}$ & $43.84(35.45 \sim 65.78)$ & $0.82(0.7 \sim 1.35)$ & 79.11(61.28 94.86) & 1.06(0.74 1.19) & $0.29(0.08 \sim 0.5)$ \\
\hline $\begin{array}{l}\text { North Africa } \\
\text { and Middle } \\
\text { East }\end{array}$ & $82.57(45.09 \sim 114.67)$ & $0.83(0.64 \sim 0.99)$ & $91.25(65.94 \sim 111.62)$ & $0.65(0.51 \sim 0.79)$ & $-1.43(-1.49 \sim-1.36)$ \\
\hline South Asia & $150.64(111.05 \sim 200.69)$ & $0.64(0.51 \sim 0.79)$ & $287.1(225.89 \sim 360.89)$ & $0.64(0.51 \sim 0.8)$ & $-0.15(-0.21 \sim-0.09)$ \\
\hline $\begin{array}{l}\text { Central Sub- } \\
\text { Saharan } \\
\text { Africa }\end{array}$ & $14.47(7.6 \sim 22.28)$ & $1.17(0.58 \sim 2.03)$ & $23.75(14.08 \sim 36.48)$ & 1.02(0.56 1.68) & $-0.83(-0.89 \sim-0.77)$ \\
\hline $\begin{array}{l}\text { Eastern Sub- } \\
\text { Saharan }\end{array}$ & $54.04(28.51 \sim 79.44)$ & 1.14(0.55 2.05) & 77.69(48.46 117.8) & $0.91(0.5 \sim 1.49)$ & $-1.2(-1.3 \sim-1.1)$ \\
\hline
\end{tabular}




\begin{tabular}{lllll}
$\begin{array}{l}\text { Southern } \\
\text { Sub-Saharan } \\
\text { Africa }\end{array}$ & $17.38(11.47 \sim 20.9)$ & $1.01(0.7 \sim 1.2)$ & $18.77(15.33 \sim 23.82)$ & $0.79(0.65 \sim 1)$ \\
$\begin{array}{l}\text { Western Sub- } \\
\text { Saharan } \\
\text { Africa }\end{array}$ & $103.62(44.84 \sim 152.58)$ & $1.2(0.73 \sim 1.76)$ & $-1.69(-2.15 \sim-1.23)$ \\
\hline
\end{tabular}

Note: DALY, disability-adjusted life years; SDI, social-demographic index; EAPC, estimated annual percentage change.

\section{Figures}

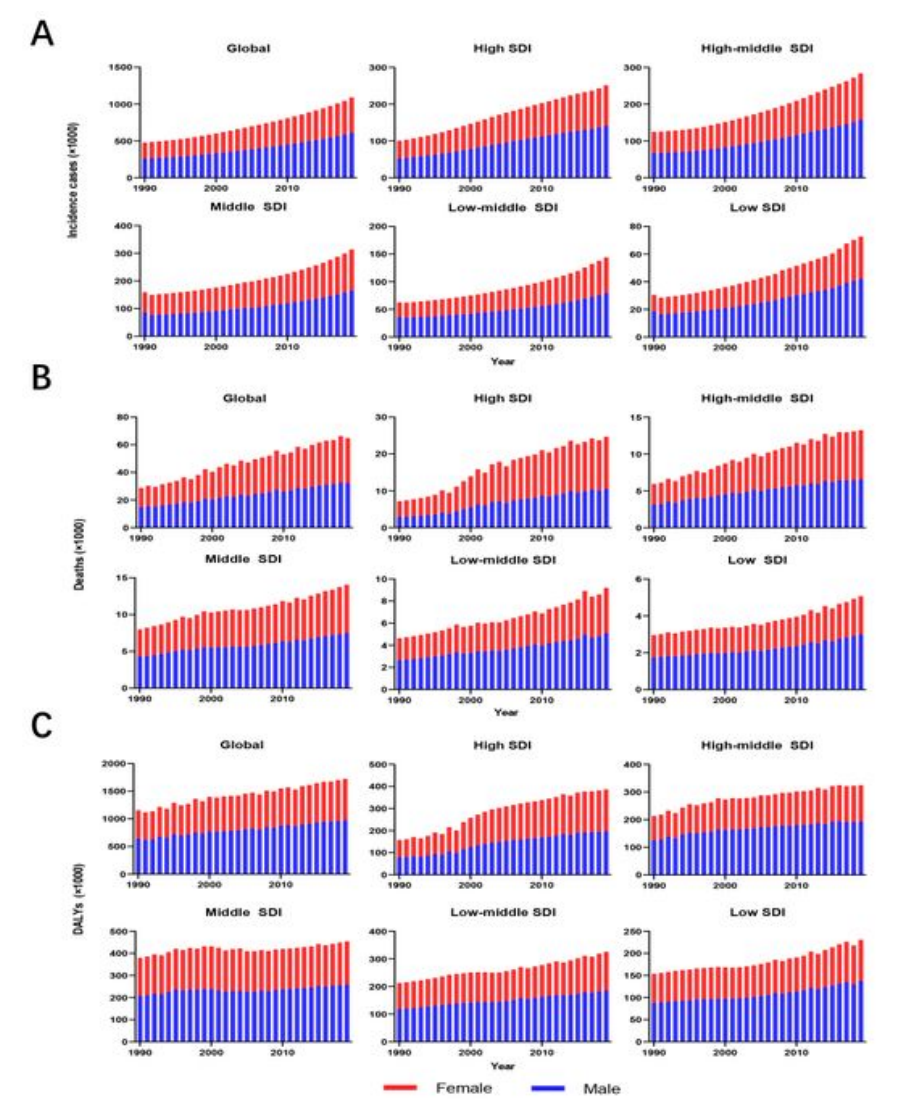

Figure 1

The change trends of infective endocarditis incidences, deaths and DALYs from 1990 to 2019. The change trends of incidences (A); the change trends of deaths (B); and the change trends of DALYs (C). Blue bars represent males, and red bars represent females. Note: DALY, disability-adjusted; SDI, socialdemographic index. 
A
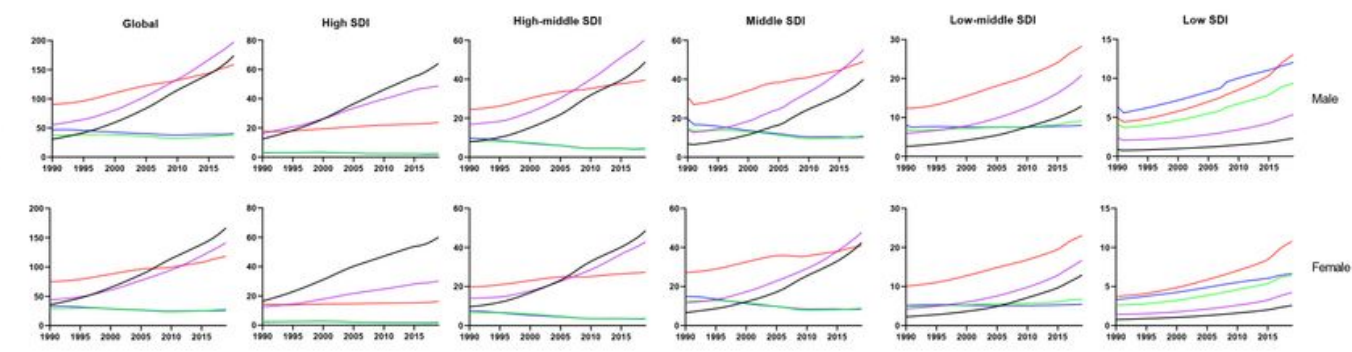

B
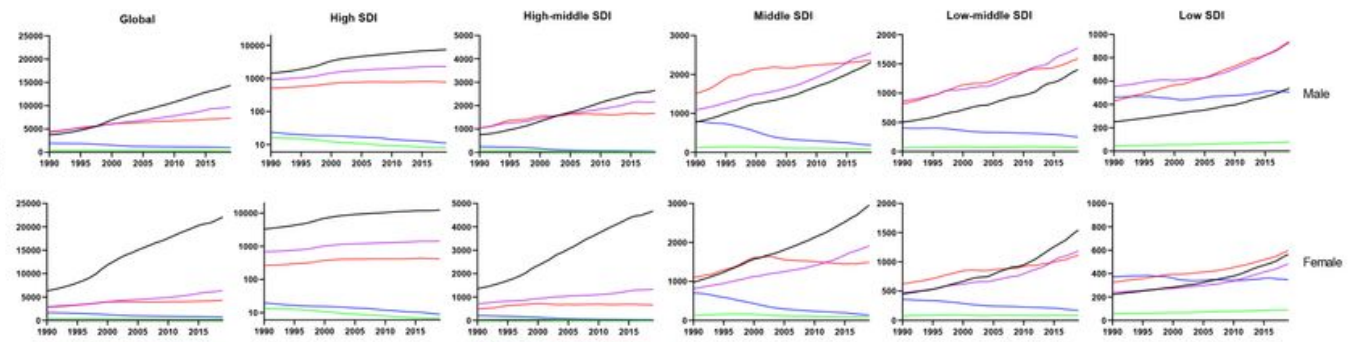

C
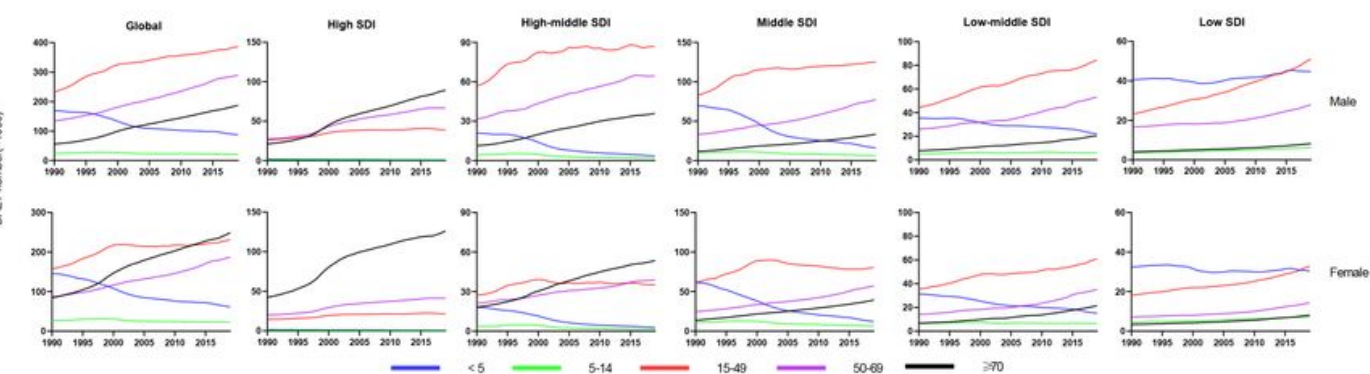

\section{Figure 2}

The change trends of infective endocarditis incidences, deaths and DALYs from 1990 to 2019 in different age groups. The change trends of incidences (A); the change trends of deaths (B); and the change trends of DALYS (C). Note: DALY, disability-adjusted; SDI, social-demographic index.

A

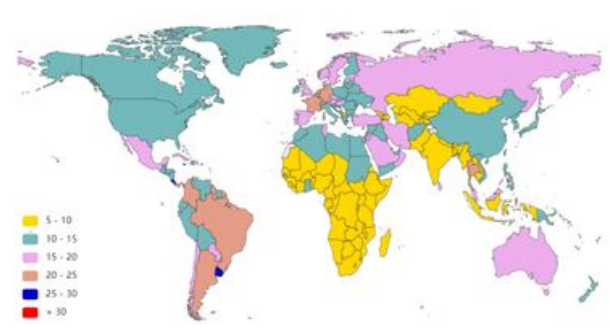

B

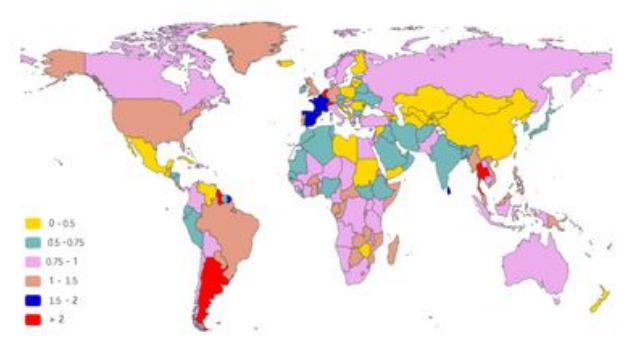

C

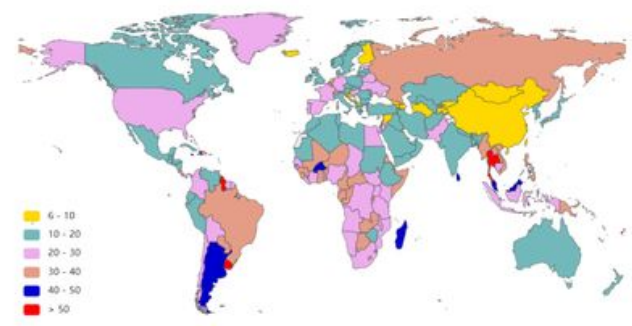

D

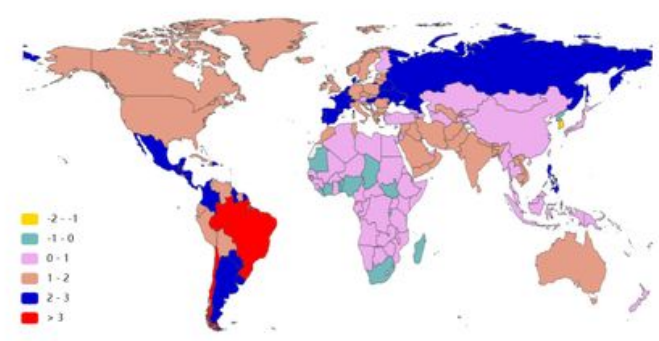

E

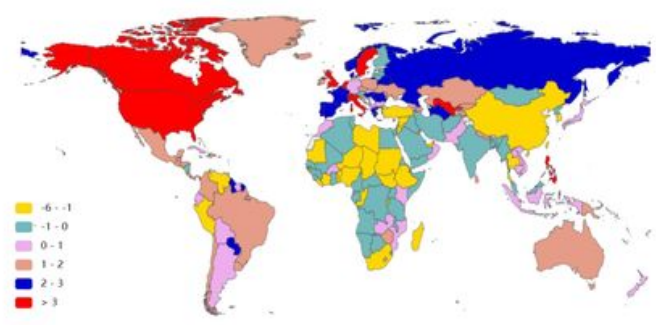

F

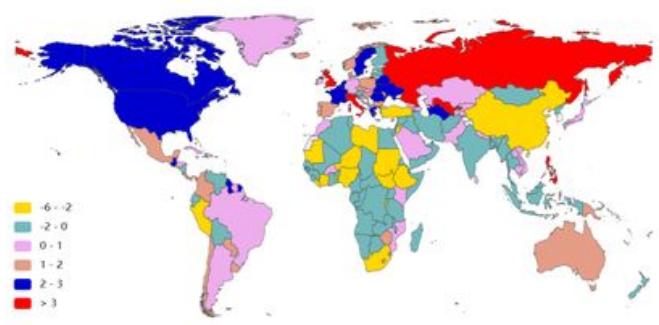

Figure 3 
The age-standardized rate of infective endocarditis in 2019 and EAPC of IE ASRs from 1990 to 2019 in 204 countries and territories. The ASIR of IE around the world in 2019 (A); The ASDR of IE across the world in 2019 (B); The age-standardized DALY rate of IE throughout the world in 2019 (C); The EAPC of ASIR (D), ASDR (E), and age-standardized DALY rate (F) in the past 30 years. Note: IE, infective endocarditis; ASIR, age-standardized incident rate; ASDR, agestandardized death rate per; DALYs, disability-adjusted life-years; EAPC, estimated annual percentage change; ASRs, age-standardized rates.

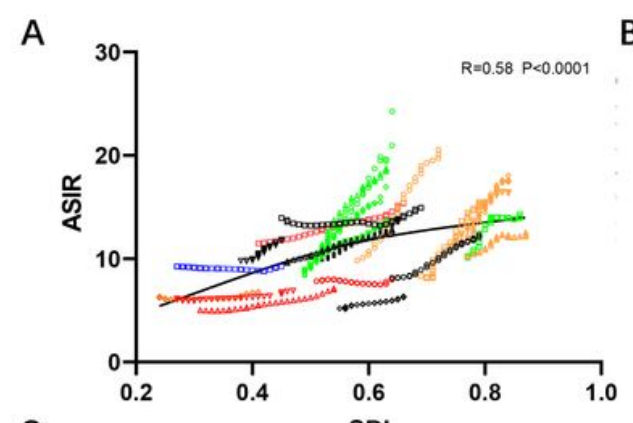

C

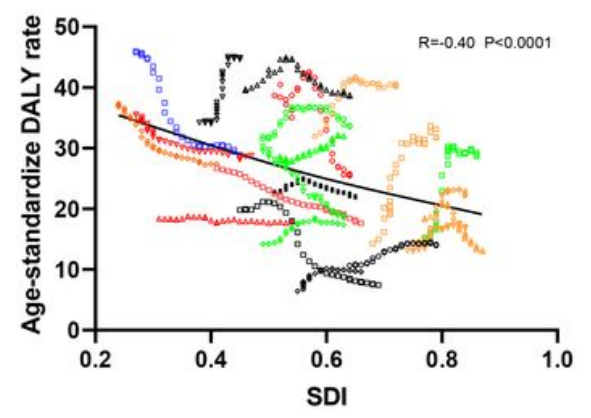

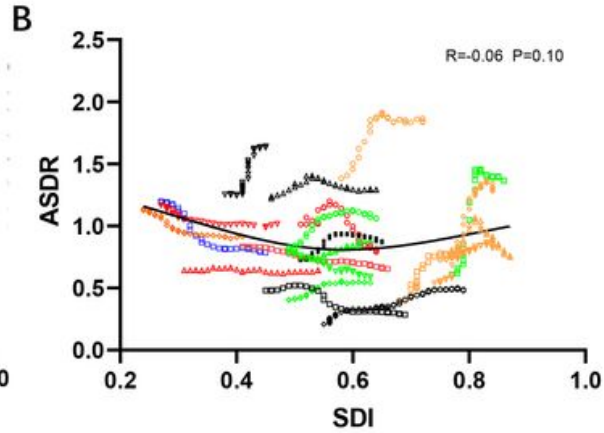

- East Asia High-income North America

$\triangle$ Southeast Asia $\quad$ Caribbean

Oceania $\quad$ Andean Latin America

Central Asia Central Latin America

- Central Europe $\quad$ Tropical Latin America

Eastern Europe $\quad$ North Africa and Middle East

High-income Asia Pacific \& South Asia

Australasia $\quad$ Central Sub-Saharan Africa

Western Europe $\quad$ Southern Sub-Saharan Africa

Southern Latin America Eastern Sub-Saharan Africa

- Gobal a Western Sub-Saharan Africa

\section{Figure 4}

Correlation analyses between ASRs of infective endocarditis and SDI in 21 regions from 1990 to 2019. The SDI was positively correlated with the ASIR (A) and negatively correlated with the age-standardized DALY rate (C) but not correlated with ASDR (B) in 21 regions from 1990 to 2019 . Note: ASRs, age-standardized rates; ASIR, age-standardized incident rate; ASDR, age-standardized death; DALYs, disability-adjusted life-years; SDI, social-demographic index. 
A

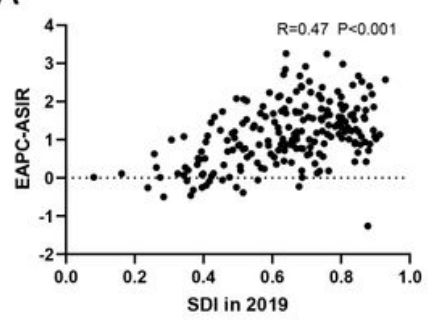

D

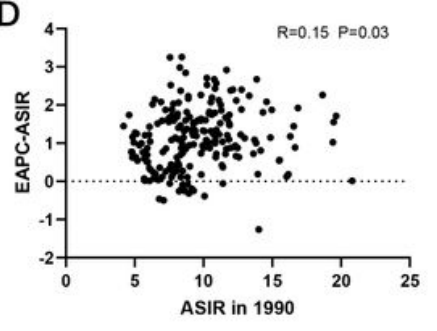

B

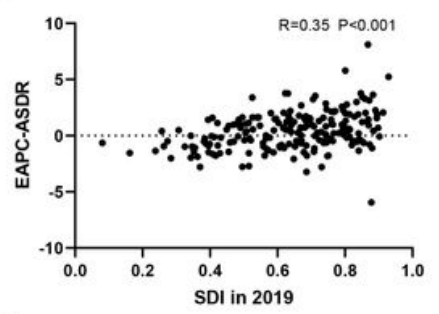

E

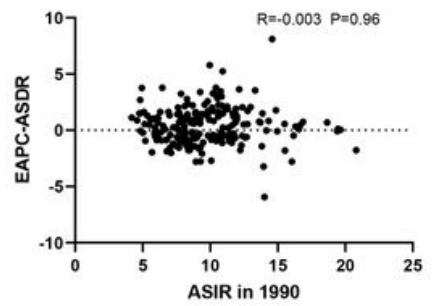

C

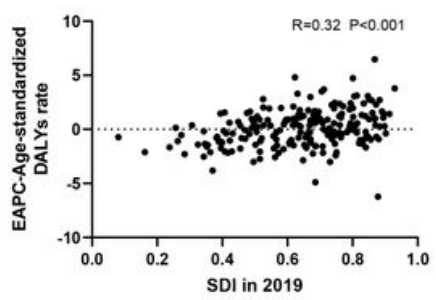

F

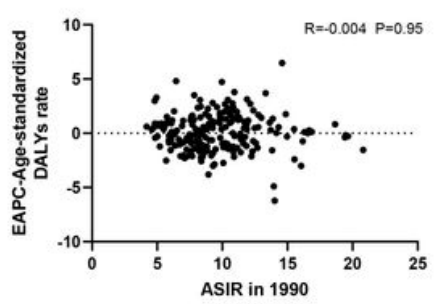

\section{Figure 5}

The correlation between EAPC and SDI in 2019 or ASIR in 1990 in 204 countries and territories. The SDI in 2019 was positively correlated with EPAC of ASIR (A), ASDR (B) and age-standardized DALY rate (C). The ASIR in 1990 presented little or no correlation with EPAC of ASIR (D), EPAC of ASDR (E) or EPAC of agestandardized DALY rate (F). Note: EAPC, estimated annual percentage change; ASIR, age-standardized incident rate; ASDR, age-standardized death rate; DALYs, disability-adjusted life-years; SDI, social-demographic index.

\section{Supplementary Files}

This is a list of supplementary files associated with this preprint. Click to download.

- Fig1supplementarydata.xlsx

- Fig2supplementarydata.xlsx

- Fig3ACsupplementarydata.xlsx

- Fig3DFsupplementarydata.xlsx

- Fig4supplementarydata.xlsx

- Fig5supplementarydata.xlsx 